EGU2020-7021

EGU General Assembly 2020

(c) Author(s) 2020. This work is distributed under

the Creative Commons Attribution 4.0 License.

\title{
Predicting the Bearing Capacity of Road Flexible Pavements using GPR
}

\author{
Chiara Ferrante ${ }^{1}$, Luca Bianchini Ciampoli ${ }^{1}$, Fabio Tosti ${ }^{2}$, Amir Morteza Alani ${ }^{2}$, and Andrea \\ Benedetto $^{1}$ \\ ${ }^{1}$ Roma Tre University, Engineering Department, Rome, Italy \\ ${ }^{2}$ University of West London (UWL), School of Computing and Engineering, London, United Kingdom
}

Most of the damage in road-flexible pavements occur where stiffness of the asphalt and loadbearing layers is low. To this extent, an effective assessment of the strength and deformation properties of these layers can help to identify the most critical sections [1].

This work proposes an experimental-based model [2] for the assessment of the bearing capacity of road-flexible pavements using ground-penetrating radar (GPR - $2 \mathrm{GHz}$ horn antenna) and the Curviameter [3] non-destructive testing (NDT) methods. It is known that the identification of early decay and loss of bearing capacity is a major challenge for effective maintenance of roads and the implementation of pavement management systems (PMSs). To this effect, a time-efficient methodology based on a quantitative modelling of road bearing capacity is developed in this study. The viability of using a GPR system in combination with the Curviameter NDT equipment is also proven.

The research is supported by the Italian Ministry of Education, University and Research under the National Project "Extended resilience analysis of transport networks (EXTRA TN): Towards a simultaneously space, aerial and ground sensed infrastructure for risks prevention", PRIN 2017, Prot. 20179BP4SM

[1] Frangopol, D.M.; Liu, M. Maintenance and management of civil infrastructure based on condition, safety, optimization, and life-cycle cost. Infrastruct. Eng. 2007, 1, 29-41.

[2] Tosti, C. L. Bianchini, F. D'Amico, A. M. Alani and A. Benedetto, "An experimental-based model for the assessment of the mechanical properties of road pavements using ground-penetrating radar," Construction and Building Materials, vol. 165, pp. 966-974, 2018.

[3] M. Simonin, J.L. Geffard, P. Hornych, Performance of deflection measurement equipment and data interpretation in France, International Symposium Non-Destructive Testing in Civil Engineering (NDT-CE) September 15-17, 2015, Berlin, Germany. 